\title{
Nerve lesions associated with shoulder dislocation; an electrodiagnostic study of 11 cases
}

\author{
JAY A LIVESON \\ From the Saul R Korey Department of Neurology, Albert Einstein College of Medicine, Bronx, New York, \\ USA
}

SUMMARY Electrodiagnostic examination of 11 patients with shoulder dislocation revealed nerve damage not previously reported. Although axillary nerve lesions were most common, posterior cord and musculocutaneous nerve damage occurred each in five cases. The mechanism of injury was important. The most surprising patterns were associated with blunt injury or recurrent spontaneous dislocation.

Shoulder dislocation can cause nerve damage. Well-known in the literature are isolated axillary nerve lesions or global brachial plexus injury, ${ }^{1-6}$ evident on clinical examination. Clinical muscle and sensory testing presents difficulties in the presence of pain associated with limb movement; this can be overcome using electrodiagnostic studies. ${ }^{7}$ A series of 11 patients with shoulder dislocation is presented with extensive electrodiagnostic evaluation. Although several patients had familiar nerve injuries, some previously unpublished patterns were documented.

\section{Subjects and methods}

Eleven cases of shoulder dislocation examined during the period 1975-1983 were reviewed. Cases with concommitant fractures in the shoulder region (except fracture/dislocation of the humeral head) were omitted. One case with preexisting acromion tip fracture was included. There were eight males and three females, ages 28 to 76 years.

Electrodiagnostic studies consisted of extensive electromyography including muscles representing all brachial plexus roots and nerves, even with no clinically evident involvement. Motor conduction, sensory nerve action potentials, and $\mathbf{F}$ wave studies were also included. ${ }^{8}$ Denervation was considered to be present if fibrillation potentials, positive sharp waves, or bizarre high-frequency potentials were detected (with less emphasis on long-duration polyphasic motor unit potentials, or decreased recruitment pattern).

Address for reprint requests: Jay A Liveson MD, 138 East 37 Street, New York, New York 10016, USA.

Received 25 October 1983 and in revised form 17 January 1984. Accepted 30 January 1984
Results (Table)

\section{INJURY MECHANISMS}

Shoulder dislocation was associated with a fall in seven cases, a "blackout" in one, and a motorcycle accident in one. Two patients had severe arm traction. One patient suffered recurrent spontaneous dislocations. Another suffered a blunt posterior blow from an 80 pound plywood beam swinging 35 feet.

\section{DISLOCATION TYPE}

There was anterior subluxation in seven patients, and downward separation in one. Three patients had fracture/dislocations. The patient injured by the beam had a separated gleno-humeral joint. In one case, no further details were available.

\section{UNDERLYING CONDITIONS}

Pre-existing abnormalities were present in five patients, including: seizures (treated with phenytoin), diffuse polyneuropathy, pre-existent cervical radiculopathy, previous scalenus operation, and a previous acromion tip fracture.

\section{TREATMENT}

In seven cases closed reduction of the dislocation was performed immediately or within 36 hours. One patient required a modified Putti-Platt procedure 18 months later. In three cases, no treatment was necessary.

NERVES INJURED

The axillary nerve was involved in all but one case 
Table

\begin{tabular}{|c|c|c|c|c|c|c|}
\hline$P t$ & $\underset{(y r)}{\operatorname{Age} / \operatorname{Sex}}$ & Injury & Shoulder lesion & Neurological lesion(s) & Treatment & Associated problems \\
\hline $\begin{array}{c}\text { Gro } \\
1 \\
2\end{array}$ & $\begin{array}{l}\operatorname{upp}_{56 / \mathrm{F}} I(\text { Axill } \\
45 / \mathrm{M}\end{array}$ & $\begin{array}{l}\text { ary lesions only) } \\
\text { Fall } \\
\text { Motorcycle accident }\end{array}$ & $\begin{array}{l}\text { Anterior subluxation } \\
\text { Fracture/dislocation } \\
\quad \text { (anterior) }\end{array}$ & $\begin{array}{l}\text { Axillary nerve } \\
\text { Axillary nerve }\end{array}$ & $\begin{array}{l}\text { Closed reduction } \\
\text { Closed reduction }\end{array}$ & Previous cervical radiculopathy \\
\hline 3 & $57 / \mathrm{M}$ & Fall & Downward separation & Axillary nerve & None & Previous scalenus operation \\
\hline \multicolumn{7}{|c|}{ Group II (Diffuse damage) } \\
\hline 4 & $73 / \mathrm{M}^{2}$ & Fall "blackout" & Anterior subluxation & $\begin{array}{l}\text { Brachial plexus (axillary, } \\
\text { musculocutaneous, radial, } \\
\text { and median nerves) }\end{array}$ & Closed reduction & "Blackouts"; Dilantin \\
\hline 5 & $46 / M$ & Fall & Anterior subluxation & $\begin{array}{l}\text { Median cord and some } \\
\text { posterior cord }\end{array}$ & Closed reduction & \\
\hline $\begin{array}{l}6 \\
7\end{array}$ & $\begin{array}{l}76 / F \\
45 / M\end{array}$ & $\begin{array}{l}\text { Fall } \\
\text { Pull }\end{array}$ & $\begin{array}{l}\text { Fracture/dislocation } \\
\text { Fracture/dislocation } \\
\text { (anterior) }\end{array}$ & $\begin{array}{l}\text { Posterior cord } \\
\text { Brachial plexus including } \\
\text { suprascapular nerve }\end{array}$ & $\begin{array}{l}\text { Closed reduction } \\
\text { Closed reduction }\end{array}$ & \\
\hline \multicolumn{7}{|c|}{ Group II (Newer entities) } \\
\hline 8 & $28 / \mathrm{M}$ & $\begin{array}{l}\text { Hit by } 80 \mathrm{lb} .(36 \mathrm{Kg}) \\
\text { object }\end{array}$ & Joint separation & $\begin{array}{l}\text { Axillary nerve plus branch } \\
\text { to triceps }\end{array}$ & None & \\
\hline 9 & $44 / M$ & Pull & Anterior subluxation & $\begin{array}{l}\text { Axillary and musculo- } \\
\text { cutaneous nerves }\end{array}$ & $\begin{array}{l}\text { Surgery } 18 \text { months } \\
\text { later }\end{array}$ & Previous acromion tip fracture \\
\hline $\begin{array}{l}10 \\
11\end{array}$ & $\begin{array}{l}\text { 69/M } \\
66 / \mathrm{F}\end{array}$ & $\begin{array}{l}\text { Fall } \\
\text { Recurrent } \\
\text { spontaneous } \\
\text { dislocations }\end{array}$ & $\begin{array}{l}\text { No details } \\
\text { Anterior subluxation }\end{array}$ & $\begin{array}{l}\text { Musculocutaneous nerve } \\
\text { Axillary and musculo- } \\
\text { cutaneous nerves }\end{array}$ & $\begin{array}{l}\text { Closed reduction } \\
\text { None }\end{array}$ & Polyneuropathy \\
\hline
\end{tabular}

(case 10); in three it was isolated. The posterior cord (axillary plus radial nerves) was injured in five cases. The entire structure was involved in two patients (cases 6,7), with segmental damage in three (cases $4,5,8)$. There was damage to the musculocutaneous nerve in five patients (cases $4,7,9,10,11$ ). In the patient with blunt trauma (case 8 ), damage focally involved the axillary nerve plus the branch to the triceps brachii, sparing other radial nerve fibres.

\section{Discussion}

Electromyography can document neurological deficit when clinical weakness or sensory deficit is difficult to evaluate. This is the case in shoulder dislocation where muscle testing is difficult because of pain on movement. It is not surprising that electromyography revealed deficits not previously reported.

Axillary nerve injury is a well-known complication, particularly on anterior dislocation. The short course around the humeral neck puts the nerve on traction with forward humeral displacement. ${ }^{6}$ In this series, all but one patient had involvement of this nerve; in three cases the lesion was isolated. The posterior cord (both axillary and radial nerves) was damaged in five patients. In one case, the lesion was isolated. In two patients there was severe widespread brachial plexus damage, with suprascapular nerve involvement in one. In another, the medial cord of the plexus was damaged. The involvement in case 8 was unique, with axillary nerve damage (undetected clinically) and damage to the branch innervating the triceps only. The injury was blunt trauma by a beam causing joint separation. In this one instance, branches innervating the triceps were damaged but more distal radial nerve fibres were spared.

Another surprising finding was musculocutaneous nerve injury in five patients; in one case it was isolated. In two instances, there was additional axillary nerve damage. In another two patients it was part of extensive brachial plexus damage. Thus, the musculocutaneous nerve seems surprisingly vulnerable to damage by shoulder dislocation. This is not wellknown; only two cases have been reported in the literature. ${ }^{910}$ Milton ${ }^{11}$ demonstrated that a combination of downward traction and external rotation places this nerve on stretch. Stevens ${ }^{10}$ described this nerve as "snubbed" at its origin in the plexus, as it traverses the coracobrachialis muscle and the fascia near the biceps. It may be injured by "side stress". In this series, other nerves were injured, but only with diffuse brachial plexus damages.

The specific injury mechanism seems to be the most significant determinant of the pattern of nerve damage. Dislocations caused by falls or arm traction may result in isolated axillary nerve lesions, or in extensive plexus damage if severe. Fracture/ dislocation may be associated with extensive plexus injury. (Pre-existent lesions did not correlate with the more extensive involvement.) In the case of spontaneous recurrent dislocations, the damage was more focal, involving the axillary and mus- 
culocutaneous nerves only. When the mechanism was a blunt shoulder blow causing glenohumeral separation, an even more focal lesion resulted, with damage localised to the axillary nerve and the branches innervating the triceps muscle only. Berry and Bril' reported different lesions in 13 patients with similar blunt shoulder trauma. There was suprascapular nerve damage in four cases, and one case of radial nerve damage. Thus in cases were the mechanism is recurrent dislocation or blunt trauma, atypical lesions should be sought.

This study demonstrates the value of electrodiagnostic studies in the evaluation of patients with shoulder dislocation. In these 11 cases not only was the axillary nerve frequently injured, but damage often occurred to the posterior cord and to the musculocutaneous nerve. These lesions occur particularly when anterior dislocation results from a fall or traction injury. When the mechanism of injury is spontaneous recurrent dislocation or blunt trauma to the shoulder, unrecognised patterns of nerve damage can occur.

\section{References}

'Watson-Jones R. Dislocation of the shoulder joint. Proc
R Soc Med 1936;29,PtII:1060-2.

${ }^{2}$ Rowe CR. Prognosis in dislocations of the shoulder. $J$ Bone Joint Surg (Am) 1956;38A:957-84.

${ }^{3}$ Gariepy R, Derome A, Laurin CA. Brachial plexus paralysis following shoulder dislocation. Can J Surg 1962;5:418-21.

${ }^{4}$ Leffert RD, Seddon H. Infraclavicular brachial plexus injuries. J Bone Joint Surg (Br) 1965;47B:9-22.

${ }^{5}$ McLaughlin HL, MacLellan DI. Recurrent anterior dislocation of the shoulder; II A comparative study. $J$ Trauma 1967;7:191-201.

${ }^{6}$ Wilson JN (ed). Watson-Jones, Fractures and Joint Injuries New York: Livingstone, 1982;545-90.

' Berry H, Bril V. Axillary nerve palsy following blunt trauma to the shoulder region: a clinical and electrophysiological review. J Neurol Neurosurg Psychiatry 1982;45:1027-32.

${ }^{8}$ Ma D, Liveson JA. Nerve Conduction Handbook Philadelphia: FA Davis, 1983.

' Seddon H. Surgical Disorders of the Peripheral Nerves, ed 2. Edinburgh: Livingstone, 1975;81-82.

${ }^{10}$ Stevens JH. Brachial plexus paralysis, In: Codman EA, ed. The Shoulder; Rupture of the Supraspinatus Tendon and other Lesions in or about the Subacromial Bursa Brooklyn: G Miller, 1934.

"Milton GW. The mechanism of circumflex and other nerve injuries in dislocation of the shoulder, and the possible mechanism of nerve injuries during reduction of dislocation. Aust NZ J Surg 1953;23:25-30. 